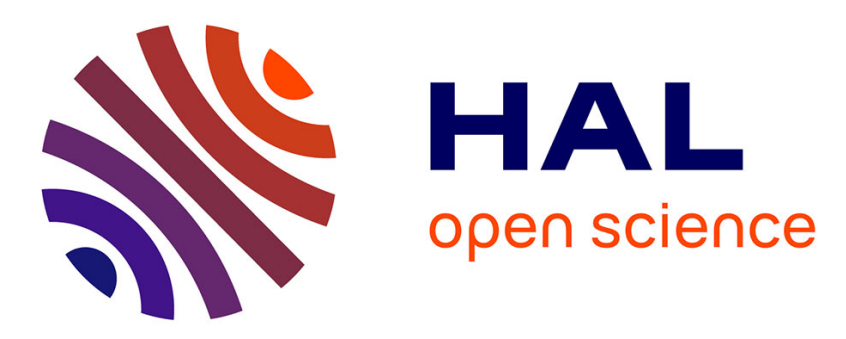

\title{
Will precious metals shine? A market efficiency perspective
}

\author{
Amélie Charles, Olivier Darné, Jae H. Kim
}

\section{To cite this version:}

Amélie Charles, Olivier Darné, Jae H. Kim. Will precious metals shine? A market efficiency perspective. International Review of Financial Analysis, 2015, 41, pp.284-291. 10.1016/j.irfa.2015.01.018 . hal-01238706

\section{HAL Id: hal-01238706 https://hal-audencia.archives-ouvertes.fr/hal-01238706}

Submitted on 6 Dec 2015

HAL is a multi-disciplinary open access archive for the deposit and dissemination of scientific research documents, whether they are published or not. The documents may come from teaching and research institutions in France or abroad, or from public or private research centers.
L'archive ouverte pluridisciplinaire HAL, est destinée au dépôt et à la diffusion de documents scientifiques de niveau recherche, publiés ou non, émanant des établissements d'enseignement et de recherche français ou étrangers, des laboratoires publics ou privés. 


\title{
Will Precious Metals Shine? \\ A Market Efficiency Perspective
}

\author{
Amélie CHARLES \\ Audencia Nantes, School of Management \\ Olivier DARNÉ \\ LEMNA, University of Nantes \\ Jae H. KIM \\ Department of Finance, La Trobe University \\ Preliminary version - Comments welcome
}




\begin{abstract}
Precious metals (gold, silver, and platinum) have become an important part of investment portfolios for individuals as well as for institutions. This paper examines the weak-form efficiency of precious metals markets, using the automatic portmanteau and variance ratio tests. It is found that return predictability of these markets has been changing over time, depending on the prevailing economic and political conditions. The return predictability of gold and silver markets have been showing downward trends, implying that the degree of the weak-form efficiency of these markets have been gradually improving. In particular, the gold market has been highly efficient recently, showing the highest degree of market efficiency among the three precious metals markets.
\end{abstract}

Keywords: Adaptive markets hypothesis; Martingale difference hypothesis; Market Efficiency; Return Predictability.

JEL Classification: G14; G15; 


\section{Introduction}

Precious metals (gold, silver, and platinum) play an important role in portfolio selection and management, and their properties have attracted much attention recently (see, for example, Conover et al. 2009; Jaffe 1989; Emmrich and McGroarty; 2013). Hillier et al. (2006) list a range of key research questions in relation to these precious metals markets, such as their roles in diversification, hedging, and risk management (see also Marshall et al., 2008; Belousova and Dorfleitner, 2012). Among these research questions, the properties of the return distributions are an issue of fundamental importance to market participants. In particular, the market efficiency (or return predictability) has strong implications to the speed of information transmission and existence of profit opportunities in these markets. Gold and silver are traditionally regarded as an "investment of last resort", while platinum is primarily used for industrial purposes as a commodity (see Hillier et al., 2006). They are becoming more and more important as an investible assets in recent years, as the degree of uncertainty of world financial markets grows. In addition, the attractiveness of gold as an investment is growing fast, with the emergence of gold exchange traded products (see Shafiee and Topal, 2010).

Hillier et al. (2006) and Daskalaki and Skiadopoulos (2011) find that all three metal returns have low correlations with stock returns, indicative of their capability as a diversification and hedging tools. They also find that the precious metals have ability to improve portfolio efficiency, in terms of higher reward-to-risk ratio. Bauer and Lucey (2010) and Bauer and McDermott (2010) find strong evidence for gold as a hedge or safe haven for stock investment. Agyei-Ampomah et al. (2014) test whether the three precious metals offer similar or better investment opportunities in the periods of market turmoil and find that silver and platinum offer investors greater compensation for their bond market losses than gold. Furthermore, Morales and Andreosso-O'Callaghan (2011) find that the precious metals markets were less affected by the Global Financial Crisis than other major financial markets around the world. Erb and Harvey (2006) and Roache and Rossi (2010) also find that gold and silver prices are counter-cyclical, implying that precious metals other than gold may also protect investors' wealth in the events of negative stock market conditions.

In this study, we examine the weak-from efficiency (or return predictability) of the precious metal markets. Despite being a fundamental issue, the efficiency of these markets has not been examined extensively in the recent literature. Under 
the weak-form efficiency, all past price and return information is fully and instantly reflected in the current price. As a result, the returns are purely unpredictable, and no investors are able to make abnormal profits consistently over time by exploiting the past price information (Fama, 1970). This property has strong implications to market participants who consider the precious metals as investible assets for the purpose of diversification, hedging, and risk management. Past empirical studies on the weak-form efficiency of precious metals markets include Tschoegl (1980), Solt and Swanson (1981), Ho (1985), Aggarwal and Soenen (1988), and Smith (2002). However, their results are now outdated, and are obtained using the statistical tests that are well-known to have undesirable small sample properties.

In order to evaluate the degree of return predictability and test for weak-from efficiency in this study, we employ the automatic variance ratio test of Kim (2009) and the automatic portmanteau test of Escanciano and Lobato (2009). These tests perform highly desirably in small samples as a means of testing for the martingale difference property (no return predictability) of asset returns (see Charles et al., 2011). In particular, these tests are robust to non-normality and (conditional) heteroscedasticity that are stylized features of precious metals returns (see, e.g., Hammoudeh et al., 2011; Cochran et al., 2012). Using a moving sub-sample window approach, we examine how the degree of return predictability has evolved over time, depending on economic, political, and financial events. This time-varying return predictability is consistent with the implications of the adaptive markets hypothesis (AMH) of Lo (2004), which is a modified version of the efficient market hypothesis of Fama (1970). An important implication of the AMH is that return predictability may arise time to time, due to changing market conditions (cycles, bubbles, crashes, crises, ...) and institutional factors. To the best of our knowledge, this study is the first that evaluates the return predictability using time-varying measures in precious metals markets, in close association with the AMH.

The main finding of the paper is that all three precious metals markets show return predictability changing over time, depending on the prevailing economic and political conditions, which is consistent with the predictions of the AMH. The gold and silver markets show a strong tendency towards the market efficiency over time. In particular, the gold market has been the most efficient, which may be the reflections of the increasingly important roles that it plays in world financial markets. In the next section, we provide a background of precious metals markets in relation to the AMH. Section 3 presents a review of the test for return predictability 
used in this paper. Section 4 presents the empirical results and Section 5 concludes the paper.

\section{Precious Metal Markets and Adaptive Mar- kets Hypothesis}

During the periods of uncertainty caused by the financial crises, certain precious metals may have desirable characteristics, such as being considered as an intrinsic store of wealth. In particular, Gold, through the centuries, has possessed unique characteristics that are comparable to a monetary unit in that it acts as a store of wealth, medium of exchange, and a unit of value (see, e.g., Goodman, 1956; Solt and Swanson, 1981). In addition, gold plays a significant role as a "flight to quality" asset during the periods of political crises, economic crises, and equity market crashes and; thus, it enjoys significant portfolio diversification properties (see, e.g., Ciner, 2001). Gold has been a traditional investment vehicle since it serves as a hedge against inflation and a safe haven in the periods of market crises (see Cai et al., 2001; Baur and McDermott, 2010; Daskalaki and Skiadopoulos, 2011; Batten et al., 2013). It has also been widely documented that gold protects investors' wealth against fluctuations in the foreign exchange value of the US dollar (Capie et al., 2005; Pukthuanthong and Roll, 2011; Reboredo, 2013; Ciner et al., 2013).

Silver is also widely used, both as a valuable industrial commodity and as an important financial instrument for inclusion in investment portfolios. It is an amazingly versatile metal that has the highly desirable qualities for various industrial uses. Technological innovations are making silver an increasingly important component of the goods such as batteries, electronics, solar energy and medicine. As the global economy expands in size and as more ways to buy silver become available, silver will continue to play a major role in the global markets (Cochran et al., 2012).

Platinum is the rarest of the precious metals and is also one of the strongest and most enduring metals. World production of platinum peaked at 514 tons in 2006 . Subsequently, production declined, with (approximately) less than five hundred tons of the metal being produced per year. Because of its internationally standardized form and purity, platinum, like gold and silver, is acceptable as a means 
of exchange. The unique physical properties of platinum make it a very desirable industrial metal, especially for jewelery and automotive industries. Platinum is also integral to the production of about $20 \%$ of all consumer goods. ${ }^{1}$

Given these unique and diverse characteristics of the precious metals markets, it is quite likely that their properties are heavily affected by the prevailing economic and political conditions. In this respect, the $\mathrm{AMH}$ provides a suitable paradigm for evaluating efficiency or return predictability of these markets. A test for efficient market hypothesis often leads to a dichotomous decision, where the market is judged to be either perfectly efficient or inefficient, which is highly unrealistic. Under the AMH, however, the market may show a departure from the state of perfect efficiency, depending on market conditions. The AMH is developed by coupling the evolutionary principle with the notion of bounded rationality (Simon, 1955). A bounded rational investor is said to exhibit satisfying rather than optimal behavior. Optimization can be costly and market participants with limited access to information or abilities to process information are merely engaged in attaining a satisfactory outcome. Lo (2004) argues that a satisfactory outcome is attained not analytically, but through an evolutionary process involving trial error and natural selection. The process of natural selection ensures the survival of the fittest and determines the number and composition of market participants. Market participants adapt to constantly changing environment and rely on heuristics to make investment choices. Based on the evolutionary perspective, profit opportunities do exist from time to time. Though they disappear after being exploited by investors, new opportunities are continually being created as groups of market participants, institutions and business conditions change.

For the precious metal markets, a number of studies have found that changing market conditions, caused by the events such as the changes in international institutional and macroeconomic factors (fluctuations of exchange rates, business cycle, monetary environment and financial market sentiment) as well as the episodes of world geopolitical tensions (e.g.,the Gulf wars, the Asian crisis, worries over Iranian nuclear plans), can affect market efficiency and other market features: see, for example, Kaufmann and Winters (1989), Rockerbie (1999), Christie-David, Chaudhry and Koch (2000), Ciner (2001), Batten, Ciner and Lucey (2010), Radetzki (1989),

\footnotetext{
${ }^{1}$ The major demands in precious metals in 2013 are: jewelry (58\%), investment (22\%) and electronics $(7 \%)$ for gold; investment (23\%), electrical and electronics $(22 \%)$ and jewelry (18\%) for silver; and autocatalyst $(37 \%)$, jewelry $(33 \%)$ and investment $(9 \%)$ for platinum.
} 
Riley (2010), Hood and Malik (2013), and Areal et al. (2014). ${ }^{2}$ These events have strong implications to the psychology of market participants and the way the markets incorporate new information into the prices, which in turn may cause time variations in serial correlation of returns.

\section{Tests for Martingale Difference Hypothesis}

As mentioned earlier, we employ the automatic portmanteau test of Escanciano and Lobato (2009) and automatic variance ratio test of Kim (2009), to test for market efficiency or return predictability in this study. The portmanteau test (Ljung and Box, 1978) and variance ratio test (Lo and MacKinlay, 1988) have been widely used in empirical finance as a means of evaluating asset return predictability. However, they are well-known to suffer from deficient properties in small samples, especially under conditional heteroskedasticity widely observed in financial data. In addition, they require ad hoc choices of the lag length or holding periods, further undermining their small sample properties. There have been a number of recent contributions to these tests, which attempt to improve their small sample properties under conditional heteroskedasticity: see, for example, Lobato et al. (2001) for the modified portmanteau test and Kim (2006) for the wild bootstrap variance ratio tests.

To overcome the problem of choosing the lag length or holding period in an ad hoc way, Escanciano and Lobato (2009) propose an automatic portmanteau (AQ) test where selection of lag length is made fully automatic based on fully datadependent procedure; and Kim (2009) proposes the use of an automatic variance ratio (AVR) test where the optimal holding period is automatically chosen. In their Monte Carlo study, Charles et al. (2011) report that the AVR and AQ tests show

\footnotetext{
${ }^{2}$ Overall, the findings on precious metals are consistent with the view of Erb and Harvey (2006, p. 69) who find that "commodity futures returns have been largely uncorrelated with one another" or that of Batten et al. (2010, p. 65) who suggest that "individual commodities are too distinct to be considered a single asset class or represented by a single index". Gold volatility is shown explained by monetary variables, but this is not true for silver. Silver volatility seems to respond strongly to the influences of the other precious metals. Platinum and palladium appear to more likely act as a financial market instrument than gold. Gold also seems to be highly sensitive to exchange rate and inflation, which implies that it is the best hedge during inflationary pressures and exchange fluctuations (Batten et al., 2010; Arouri et al., 2012).
} 
highly desirable small sample (size and power) properties, under a wide range of conditionally heteroskedastic asset returns. This section presents brief details of the these automatic tests.

\subsection{Automatic Portmanteau Test}

Let $Y_{t}$ denote asset return at time $t$, where $t=1, \ldots, T$. Under the null hypothesis of no asset return predictability, $Y_{t}$ is a strictly stationary and ergodic martingale difference sequence (MDS) with appropriate moment conditions (see Escanciano and Lobato, 2009; Assumption A1). The original portmanteau test statistic is written as

$$
Q_{p}=T \sum_{i=1}^{p} \widehat{\rho}^{2}(i),
$$

where $\hat{\rho}(i)$ is the sample autocorrelation of $Y_{t}$ of order $i$. When $Y_{t}$ shows conditional heteroscedasticity, Lobato et al. (2001) propose the use of a robustified test statistic of the form

$$
Q_{p}^{*}=T \sum_{i=1}^{p} \widetilde{\rho}^{2}(i),
$$

where $\widetilde{\rho}(i)=\widehat{\gamma}^{2}(i) / \widehat{\tau}(j), \widehat{\gamma}(i)$ is the sample autocovariance of $Y_{t}$ of order $i$, and $\widehat{\tau}(i)$ is the sample autocovariance of $Y_{t}^{2}$ of order $i$.

The choice of $p$ should be made to implement the test. In order to avoid an $a d$ hoc selection, Escanciano and Lobato (2009) propose an automatic test where the optimal value of $p$ is determined by a fully data-dependent procedure. The test statistic, which asymptotically follows the $\chi_{1}^{2}$ distribution under the null hypothesis, is written as

$$
A Q=Q_{\widetilde{p}}^{*}
$$

where $\widetilde{p}=\min \left\{p: 1 \leq p \leq d ; L_{p} \geq L_{h}, h=1,2, \ldots, d\right\}$ and $d$ is a fixed upper bound, while $L_{p}=Q_{p}^{*}-\pi(p, T)$, where the penalty term $\pi(p, T, q)=p \log (T)$ if $\max _{1 \leq i \leq d} \sqrt{T}|\widetilde{\rho}(i)| \leq \sqrt{2.4 \log (T)}$ and $\pi(p, T, q)=2 p$ if otherwise. Note that the penalty term is a balance between AIC and BIC. The null hypothesis of no return predictability is rejected at $\alpha$ level of significance, if the $A Q$ statistics is greater 
than its asymptomatic critical value $\chi_{1, \alpha}^{2}$, which is the $100(1-\alpha)$ th percentile of the $\chi_{1}^{2}$ distribution.

\subsection{Automatic Variance Ratio Test}

The variance ratio test is based on the statistic of the form

$$
\widehat{V R}(k)=1+2 \sum_{i=1}^{k-1}\left(1-\frac{i}{k}\right) \widehat{\rho}(i),
$$

where $k$ denotes the holding period. Under the null hypothesis of no return predictability, a standardized version of (4) asymptotically follows the standard normal distribution (Lo and MacKinlay, 1988). However, the test often requires an ad hoc choice of the value of $k$. Choi (1999) proposes an automatic variance ratio (AVR) test where $k$ is chosen optimally using a fully data-dependent method of Andrews (1991). Kim (2009) finds that small sample properties of Choi's (1999) test can be substantially improved under conditional heteroskedasticity, by employing the wild bootstrap of Mammen (1993).

Let the AVR test statistic with the optimal choice of $k$ be denoted as $A V R\left(k^{*}\right)$. Kim's (2009) wild bootstrap AVR test is conducted in three stages as follows:

1. Form a bootstrap sample of size $T$ as $Y_{t}^{*}=\eta_{t} Y_{t}(t=1, \ldots, T)$, where $\eta_{t}$ is random variable with zero mean and unit variance;

2. Calculate $A V R^{*}\left(k^{*}\right)$, the $A V R\left(k^{*}\right)$ statistic calculated from $\left\{Y_{t}^{*}\right\}_{t=1}^{T}$;

3. Repeat 1 and $2 B$ times, to produce the bootstrap distribution of the AVR statistic $\left\{A V R^{*}\left(k^{*} ; j\right)\right\}_{j=1}^{B}$.

It can be shown that the bootstrap sample $\left\{Y_{t}^{*}\right\}_{t=1}^{T}$ is serially uncorrelated, while effectively replicating the heteroscedastic structure of the asset return $Y_{t}$. As a result, the bootstrap distribution $\left\{A V R^{*}\left(k^{*} ; j\right)\right\}_{j=1}^{B}$ provides a small-sample approximation to the sampling distribution of $A V R\left(k^{*}\right)$ statistic, under the null hypothesis.

The test for the null hypothesis of no return predictability can be conducted using the confidence interval for the population value of $V R$ under the null hypothesis. That is, let $A V R_{\tau}^{*}$ be the $\tau$ th percentile of $\left\{A V R^{*}\left(k^{*} ; j\right)\right\}_{j=1}^{B}$. Then, $100(1-\alpha)$ percent confidence interval for the population variance ratio under $H_{0}$ is constructed as $\left[A V R_{0.5 \alpha}^{*}, A V R_{1-0.5 \alpha}^{*}\right]$. If the $A V R\left(k^{*}\right)$ statistic lies outside the $100(1-\alpha)$ percent confidence interval, the null hypothesis of no return predictability 
is rejected at $\alpha$ percent level of significance. For $\eta_{t}$, we use the two point distribution proposed by Mammen (1993). The number of bootstrap replications $B$ is set at 500 in this study, which is well-known to be sufficient for the construction of bootstrap confidence interval.

\subsection{Measuring the Degree of Return Predictability}

The $A Q$ and $A V R\left(k^{*}\right)$ tests described above are used to evaluate statistical significance of return predictability. However, evaluation of effect size is also important, which in this case represents the magnitude of the degree of return predictability. Note that the $A Q$ and $A V R\left(k^{*}\right)$ statistics can be used as natural measures of return predictability $^{3}$. Since the $A Q$ statistic is the sum of squared sample autocorrelations of $Y_{t}$ to the optimal order (scaled by the sample size), a higher value of $A Q$ statistic indicates a higher degree of return predictability. Similarly, the $A V R\left(k^{*}\right)$ statistic is one plus a weighted sum of the autocorrelations to the optimal order, with positive and declining weights. The main difference between the $A Q$ and $A V R\left(k^{*}\right)$ statistics is that the former treats all sample autocorrelations to the optimal order with equal weights, while the latter provides higher weights to lower order sample autocorrelations. An attractive feature of the $A V R\left(k^{*}\right)$ statistic is that it reveals the sign of overall autocorrelations of asset return. That is, the value of $A V R\left(k^{*}\right)$ greater (less) than one indicates overall positive (negative) autocorrelations of asset return. This sign can be an important indicator to profit-seeking investors, as it provides a key signal to which trading strategies they should adopt (e.g., momentum vs. contrarian strategies).

\section{Empirical Results}

In this section, we present the data details and their descriptive properties. We also present the empirical results and discuss their implications.

\subsection{Data and Computational Details}

The sample data consists of daily closing spot prices and their log returns for gold, silver and platinum. The data spans from January 3, 1977 to October 23, 2013,

\footnotetext{
${ }^{3}$ Griffin et al. (2010) use the absolute value of $V R(k)-1$ as a measure of return predictability.
} 
with a total of 9,603 observations. ${ }^{4}$ The data are obtained from Thomson Financial Datastream. Figure 1 displays the metal prices and their log returns. All three prices show instability around 1980, especially with the silver. All three prices are relatively stable until about 2005, where they all show clear upward trends. Similarly, the returns show high volatility in the early 1980's, followed by a long period of relative stability. From around 2005, the volatility becomes to a degree higher for all three metals. The period from 2005 represents the timing of US housing bubble, commodities boom, and the Global Financial Crisis, which have strong impact on the psychology of the markets for all financial assets including those of the precious metals.

We first present descriptive statistics for the return series calculated as the first logarithmic difference of the daily closing prices in Table 1 (see Figure 1). The results reveal that gold and platinum display higher mean returns than silver. In terms of standard deviation, gold exhibits the least volatility, while silver displays the highest volatility. All returns series display significant skewness, with negative skewness for gold and platinum and positive skewness for silver, indicating that the empirical distributions of the returns exhibit asymmetric shape (with longer left tail for gold and platinum). Excess kurtosis is observed for all return series, showing that their empirical distributions are leptokurtic, i.e. with substantially fatter tails (than the normal distribution). The Jarque-Bera test statistic is significant at the $1 \%$ level of significance for all series, indicating that the precious metal returns are highly non-normal. We also conduct the LM test for ARCH conditional heteroscedasticity $^{5}$, with the strong evidence of conditional heteroscedasticity. Note that the tests for the MDH or return predictability presented in the previous section, which we employ for our empirical analysis, are found to show desirable size and power properties in small samples under non-normality and conditional heteroskedasticity (see Charles, et al. 2011).

To evaluate time-varying return predictability, we use moving sub-sample window of 2 years, which consists of approximately 520 daily observations. This sample size is large enough to ensure desirable size and power properties of the tests em-

\footnotetext{
${ }^{4}$ The sample period starts in $\mathbf{1 9 7} 7$ because the spot prices are available in a daily frequency for the three precious markets. Gold and platinum are available earlier but in weekly data. Palladium is excluded because the data are available since 1987.

${ }^{5}$ The LM test is applied on the residuals of the ARMA model, where the lag length is selected based on the Akaike information criterion.
} 
ployed (see Charles et al., 2011). The 2-year window is also suitable to capture the effects of changing market conditions. The first sub-sample window covers the period from January 1977 to December 1978. Then, the window moves forward by one month to cover the period of February 1977 to January 1979. The process continues to the end of data set. Through this process, we obtain monthly measures of time-varying return predictability. In this way, the periods or episodes of high degree of return predictability (with statistical significance) is identified, which in turn are related to the corresponding events and shocks. Note that the use of moving sub-sample window approach is not intended for multiple testing in this paper, but adopted as a means of measuring the degree of return predictability over time. It is also an effective guard against data snooping bias (see Hsu and Kuan, 2006).

Table 1: Descriptive statistics for daily returns

\begin{tabular}{lcccccc}
\hline \hline & Mean $(\times 100)$ & Std. dev. & Skewness & Kurtosis & JB & ARCH $(10)$ \\
\hline Gold & 0.024 & 0.012 & $-0.41^{*}$ & $17.22^{*}$ & $13980.7^{*}$ & $1212.9^{*}$ \\
Silver & 0.017 & 0.024 & $0.05^{*}$ & $37.96^{*}$ & $39068.3^{*}$ & $2823.2^{*}$ \\
Platinum & 0.024 & 0.017 & $-0.47^{*}$ & $12.68^{*}$ & $8339.1^{*}$ & $1177.6^{*}$ \\
\hline \hline
\end{tabular}

Note: * indicates statistical significance at the $5 \%$ level. JB and $\mathrm{ARCH}(10)$ are the Jarque-Bera test for normality and the LM test for conditional heteroscedasticity, respectively.

\subsection{Evaluating time-varying return predictability}

Figures 2-3 report the AQ and AVR test statistics obtained from moving subsample windows, monthly from January 1979 to November 2013. For the AQ statistic, the horizonal line indicate the $5 \%$ asymptotic critical value of 3.89 . The $\mathrm{AQ}$ value greater than the critical value indicates the rejection of the null hypothesis of MDH. For the AVR tests, the AVR statistics are plotted along with their 95\% confidence intervals under the null hypothesis. If an AVR value lies outside the confidence interval, the null hypothesis of MDH (no return predictability) is rejected at $5 \%$ level of significance, which is evidence against weak-from efficiency of the market. As mentioned earlier, the AVR value less (greater) than 1 indicates the overall negative (positive) return autocorrelations. 
The overall results indicate that all precious metals returns have been predictable in a number of periods. This means that the precious metals markets often show departure from market efficiency from time to time, which is consistent with the implications of the AMH. The gold market, however, has an extensive period of no return predictability in 2000's, while the silver and platinum markets have become mostly efficient from around 2005. All three returns have been showing predictable episodes depending on various economic events, with downward trend in return predictability. These findings are consistent with the prediction of the AMH of Lo (2004).

We also find strong evidence that the episodes of return predictability are closely related with the prevailing economic and market conditions. The first and second columns of Table 2 provide a summary of the events that may have affected the precious metals markets in the chronological order. For gold, the AQ and AVR tests reject the $\mathrm{MDH}$ in 1982 . The timing corresponds to the US tight monetary policy, leading to a recession and high interest rates in 1982, which also coincide with the timing of the intervention of the Reagan administration for concerted interventions with major central banks to slow down the appreciation of the dollar. As the sub-sample window moves to 1985, both tests reject the MDH for gold, which coincides with tensions in South African gold mines.

For the silver market, both tests reject the MDH during the period 1978-1979 which can be explained by the silver manipulation due to the Hunt brothers to corner the silver market. ${ }^{6}$ The rejection of the MDH by the AQ test at the end of 1984 coincides with the opening of the silver options market on the Commodity Exchange in October 1984, in which traders will be able to trade exchange-traded options on Comex's silver futures at prices determined by a continuing auction and not by dealer fiat. As the subsample window moves to 1989, the AQ and AVR tests reject the MDH with high level of dollar in 1989, the invasion of Kuwait by Iraq in August 1990, and the Operation Desert Storm in January 1991. Contraction in demand from jewelery, photographic and electronic industries, coupled with rising in supply from Mexico and Peru, may be closely related with the rejection of MDH for silver in the beginning of 2000s.

The AQ and AVR tests reject the MDH for platinum at the end of 1984 . The

\footnotetext{
${ }^{6}$ The largest single day drop in the price of silver occurred on Silver Thursday (March 27, 1980), leading panic on commodity markets.
} 
timing corresponds to the filing under Chapter 11 of the bankruptcy code in December 1984 of Deak \& Company, one of the largest company of precious metal dealers. The MDH is rejected for the platinum market when the sub-sample window moves forward to the end of 1988 after Ford Motor Company announced a pilot program to eliminate the precious metal from catalytic converters. Both tests started to move to the rejection region in the beginning of 2000 for platinum with high demand from automotive and jewelery industries and the Russian restricting policy in delivery (exportation). The AQ test rejects the MDH from the mid 2002 with increasing automotive industrial demand and problems of production due to fear of tensions (strikes) in Russian and South African producers. The AVR test rejects the MDH from the beginning of 2007 with high demand from jewelery and automobile industries, and low level of the South African mining production.

For all three precious metals, the AQ and AVR tests start to move to the rejection region from the end of 1992, indicating a strong deviation from the MDH with inflation fears and expectations for higher interest rates in the US, and the Mexican political assassination (presidential candidate Colosio). The MDH is rejected by both tests for gold and silver when the sub-sample window moves forward to 1997 with the Asian and Russian crises. The announcements of central banks to support the economy can explain the rejection of the $\mathrm{MDH}$ for platinum by the AVR test from the mid-2012. Further, the AVR test rejects the MDH for platinum in mid2013 with possible changes in monetary policy announced by the Fed Chairman Ben Bernanke and fears of economic slowdown. The rejection of MDH from the AVR test for silver and platinum at the end of 2013 can be explained by bad news on US economy and the fall of the dollar.

To conduct a systematic evaluation of how these events affect the degree of return predictability, we regress the AVR statistics reported in Figure 3 against the dummy variables corresponding to the events listed in Table 2. The coefficients and their statistical significance are reported in Table 2 for three precious metals. For all three regressions, the intercept coefficients are fairly close to one, especially for the gold and platinum, which indicates that the returns of these precious metals show little autocorrelations (market efficiency), when all dummy variables jointly take the value of 0 . This means that these markets are efficient in the weak-form during normal times. The intercept coefficient of AVR regression for silver is somewhat lower than 1 (0.822), consistent 
with the overall negative autocorrelation observed in Figure 3. For all cases, most of dummy variables are statistically significant at the conventional levels of significance, implying that the events listed in Table 2 are closely related with the periods of non-zero autocorrelations. For the gold, the events with large effect size (coefficient estimates) include the Silver Thursday, US tight monetary policy and US dollar intervention, and tensions in South African mines, which all show negative impact on the value of AVR statistic. For the silver and platinum, the Silver Thursday, Deak \& Company Bankruptcy, High US dollar, High Demand for Platinum and Russian Restricting policy, and High Demand and low Production in 2007 are the events with large effects on the AVR statistic. The above results are consistent with our earlier observations that the precious metals markets are efficient in the weak-form, but departures from efficiency occur from time to time depending on the prevailing economic and financial conditions.

\subsection{Further Discussions}

As observed above, the gold and silver markets exhibit a downward trend in return predictability. This feature is particularly clear in Figure 2, where the AQ statistics decline over time. This means that the degree of pricing efficiency has gradually improved from the late 1970's. This is consistent with the gradual improvement in the efficiency of the U.S. stock market from the early 1980's, reported in Gu and Finnerty (2002) and Kim et al. (2011). The latter authors attribute this to the technological innovations in financial markets and stability of U.S. macroeconomic fundamentals, which may also have influenced the precious metals markets. In contrast with the gold and silver markets, the platinum market does not exhibit such a downward trend of return predictability.

The higher degree of efficiency of gold market may be strongly related with the fact that it is the biggest market of all three metals, with an average of trading volume of US $\$ 32.5$ billion for gold against US $\$ 4.5$ billion and US $\$ 0.8$ billion for silver and platinum, respectively, on the 2006-2010 period (World Gold Council, 2011). It is also becoming an attractive and important investment product for a range of investors in the financial market for diversification and hedging purposes. Investing in gold is becoming easier via gold Exchange Traded Funds (ETFs) compared to 
other finance markets (Shafiee and Topal, 2010). The gold ETFs have stimulated the demand side of gold because it has become as easy to trade as it is to trade any stock or share (World Gold Council, 2008). The gold demand for the ETFs was US $\$ 1.7$ billion in 2004 and US $\$ 279$ billion in 2012 (World Gold Council, 2013). Further, in 2008, 65\% of all Exchange Traded Commodities (ETCs) are exposed to gold, with the remaining $35 \%$ exposed to other commodities. Gold's dominance is partly due to the fact that it was the first ETC to be created. ${ }^{7}$ In addition, this provides easily accessible information for investors about the general market for gold to use in their decision making. Furthermore, investor demand for silver ETFs rose since 2006, as the silver ETF holding was 100 millions ounces (Moz) of silver in 2006, $400 \mathrm{Moz}$ in 2009 and $600 \mathrm{Moz}$ in 2013 (The Silver Institute, 2014). This can explain that gold and silver have been becoming more efficient but not for platinum. For comparison, the ETF holdings of gold, silver and platinum were 55.5, 635.5 and 2.7 Moz, respectively, in May 2014 (Bloomberg). Further, the most of the demand for platinum (more than $\mathbf{8 0 \%}$ ) is attributable to the industrial sector, in particular the automotive industry. and therefore is more affected by economic environment, such as the Great recession.

According to the AVR statistics reported in Figure 3 and Table 2, these metal returns are characterized by negative overall autocorrelations more often than positive ones. This feature is particulary strong for the silver market. In particular, for all markets, when the AVR statistics are statistically significant, they are mostly negative as evident from Table 2. The presence of negative autocorrelation can be explained by the overreaction hypothesis. The foundation of this hypothesis originated in applied psychology's overreaction hypothesis, which predicts that people tend to overreact to dramatic news and events, regardless of whether these events are positive or negative in nature. This would lead to excessive optimism over good news and extreme pessimism over bad news (De Bondt and Thaler, 1985, 1987). As a result, prices tend to overshoot, causing mispricing to occur. Prices would deviate temporarily from their intrinsic values, originating in the medium-long term

\footnotetext{
${ }^{7}$ On March 28, 2003, the first gold-backed ETF, developed by ETF Securities, was launched. It trades on the Australian stock exchange as the ETFS Physical Gold. Globally, there are now 143 gold ETFs available. The first ETF for silver (iShares Silver Trust launched on the NYSE) and platinum (on the SWX Swiss Exchange) were launched in April 2006 and in April 2007, respectively.
} 
a mean-reverting effect. ${ }^{8}$ It is not clear economically why these precious metals market show negative autocorrelation from time to time. While it may be related with their properties such as safe haven assets and hedging tools, this issue deserves further investigation and is left for future research.

\section{Conclusion}

Precious metals are important components of investment portfolios for individuals as well as for institutions, due mainly to their effectiveness as a hedge or safe haven. A key question to many investors and traders is whether these precious metals are priced efficiently, which is a fundamental property of their return distributions over time. Given the accumulated evidence that these markets are heavily influenced by economic and political conditions, it is highly likely that the degree of market efficiency (or return predictability) change over time depending on such conditions

This paper examined the weak-form efficiency of three precious metals (gold, silver, platinum) markets, in close association with Lo's (2004) adaptive markets hypothesis. Using the daily data from 1977 to 2013, we calculate the monthly measures of return predictability and conduct the tests for no return predictability over time. For this purpose, we employ the automatic portmanteau test of Escanciano and Lobato (2009) and automatic variance ratio test of Kim (2009), which possess desirable small sample properties (see Charles et al., 2011). The main finding of our study is that the three markets show time-varying return predictability over time, and their degree of predictability depends heavily on the prevailing economic and political conditions. This finding is consistent with the implications of the adaptive markets hypothesis. The degrees of return predictability of the gold and silver markets show a strong downward trend, which indicates that these markets have been gradually becoming more efficient over time. In particular, the gold market has been the most efficient, which may be strongly related with its attractiveness as an investible asset and its effectiveness as a vehicle for risk management.

\footnotetext{
${ }^{8}$ Recently, Aggarwal et al. (2014) document that gold forward markets overreact.
} 


\section{References}

[1] Aggarwal, R., Lucey, B.M., O'Connor, F.A. (2014). Rationality in precious metals forward markets: Evidence of behavioural deviations in the gold markets. Journal of Multinational Financial Management, forthcoming.

[2] Aggarwal, R., Soenen., L. (1988). The nature and efficiency of the gold market. Journal of Portfolio Management, 14, 18-21.

[3] Agyei-Ampomah, S., Gounopoulos, D., Mazouz, K. (2014). Does gold offer a better protection against losses in sovereign debt bonds than other metals? Journal of Banking and Finance, 40, 507-521.

[4] Andrews, D.W.K. (1991). Heteroskedasticity and autocorrelation consistent covariance matrix estimation. Econometrica, 58, 817-858.

[5] Areal, N., Oliveira, B., Sampaio, R. (2014). When times get tough, gold is golden. The European Journal of Finance, forthcoming.

[6] Arouri, M., Hammoudeh, S., Lahiani, A., Nguyen, D.C. (2012). Long memory and structural breaks in modeling the return and volatility dynamics of precious metals. The Quarterly Review of Economics and Finance, 52, 207-218.

[7] Batten, J.A., Ciner, C., Lucey, B.M. (2010). The macroeconomic determinants of volatility in precious metals markets. Resources Policy, 35, 65-71.

[8] Batten, J.A., Ciner, C., Lucey, B.M. (2013). On the economic determinants of the gold-inflation relation. Working Paper.

[9] Baur, D.G., Lucey, B. (2010). Is gold a hedge or a safe haven? An analysis of stocks, bonds and gold. The Financial Review, 45, 217-229.

[10] Baur, D.G., Mcdermott, T.K., (2010). Is gold a safe haven? International evidence. Journal of Banking and Finance, 34, 1886-1898.

[11] Belousova, J., Dorfleitner, G. (2012). On the diversification benefits of commodities from the perspective of euro investors. Journal of Banking and Finance, 36, 2455-2472.

[12] Cai, J., Cheung, Y.-L., Wong, M.C.S. (2001). What moves the gold market? Journal of Futures Markets, 21, 257-278.

[13] Capie, F., Mills, T.C., Wood, G. (2005). Gold as a hedge against the dollar. Journal of International Financial Markets, Institution and Money, 15, 343352. 
[14] Charles, A., Darné, O., Kim, J.H. (2011). Small sample properties of alternative tests for martingale difference hypothesis. Economics Letters, 110, 151154 .

[15] Christie-David, R., Chaudhry, M., Koch, T.W. (2000). Do macroeconomics news releases affect gold and silver prices? Journal of Economics and Business, $52,405-421$.

[16] Choi, I. (1999). Testing the random walk hypothesis for real exchange rates. Journal of Applied Econometrics 14, 293-308.

[17] Ciner, C. (2001). On the long-run relationship between gold and silver: A note. Global Finance Journal, 12, 299-303.

[18] Ciner, C., Gurdgiev, C., Lucey, B.M. (2013). Hedges and safe havens: an examination of stocks, bonds, gold, oil and exchange rates. International Review of Financial Analysis, 29, 202-211.

[19] Cochran, S.J., Mansur, I., Odusami, B. (2012). Volatility persistence in metal returns: A FIGARCH approach. Journal of Economics and Business, 64, 287305.

[20] Conover, C.M., Jensen, G.R., Johnson, R.R., Mercer, J.M., (2005). Can Precious Metals Make Your Portfolio Shine? Financial Analysts Journal, 46 (July/August 1990), pp. 76-79.

[21] Daskalaki, C., Skiadopoulos, G. (2011). Should investors include commodities in their portfolios after all? New evidence. Journal of Banking and Finance, $35,2606-2626$.

[22] De Bondt, W.F.M., Thaler, R. (1985). Does the stock market overreact? Journal of Finance, 40, 793-805.

[23] De Bondt, W.F.M., Thaler, R. (1987). Further evidence of overreaction and stock market seasonality. The Journal of Finance, 42, 557-581.

[24] Emmirich, O., McGroarty, F.J. (2013). Should gold be included in institutional investment portfolios?, Applied Financial Economics, 23(19), 15531565.

[25] Erb, C.B., Harvey, C.R. (2006). The strategic and tactical value of commodity futures. Financial Analysts Journal, 62, 69-97.

[26] Escanciano, J.C., Lobato, I.N. (2009). An automatic portmanteau test for serial correlation. Journal of Econometrics, 151, 140-149. 
[27] Fama, E. (1970). Efficient capital markets: A review of theory and empirical work. Journal of Finance, 25, 383-417.

[28] Goodman, B. (1956). The price of gold and international liquidity. Journal of Finance, 11, 15-28.

[29] Griffin, J.M., Kelly, P.J., Nardari, F., 2010. Do market efficiency measures yield correct inferences? A comparison of developed and emerging markets. Review of Financial Studies 23(8), 3225-3277.

[30] Gu, A.Y., Finnerty, J. (2002). The evolution of market efficiency: 103 years daily data of Dow. Review of Quantitative Finance and Accounting, 18, 219237.

[31] Hammoudeh, S., Malik, F., McAleer, M. (2001). Risk management of precious metals. The Quarterly Review of Economics and Finance, 51, 435-441.

[32] Hillier, D., Draper, P., Robert, F. (2006). Do precious metals shine? An investment perspective. Financial Analysts Journal, 62, 98-106.

[33] Ho, Y.-K. (1985). Test of the incrementally efficient market hypothesis for the London gold market. Economics Letters, 19, 67-70.

[34] Hood, M., Malik, M. (2013). Is gold the best hedge and a safe haven under changing stock market volatility? Review of Financial Economics 22, 4752.

[35] Jaffe, J. F. (1989). Gold and gold stocks as investments for institutional portfolios, Financial Analysts Journal, 45, 539.

[36] Kaufmann, T.D., Winters, R.A. (1989). The price of gold: A simple model. Resources Policy, 15, 309-313.

[37] Kim, J.H. (2006). Wild bootstrapping variance ratio tests. Economics Letters, $92,38-43$.

[38] Kim, J.H. (2009). Automatic variance ratio test under conditional heteroskedasticty. Finance Research Letters, 3, 179-185.

[39] Kim, J.H., Shamsuddin, A. (2008). Are Asian stock markets efficient? Evidence from new multiple variance ratio tests. Journal of Empirical Finance, $15,518-532$.

[40] Kim, J.H., Shamsuddin, A., Lim, K.P. (2011). Stock return predictability and the adaptive markets hypothesis: Evidence from century long U.S. Data. Journal of Empirical Finance, 18, 868-879. 
[41] Ljung, G.M., Box, G.E.P., (1978). On a measure of lack of fit in time series models. Biometrika, 65, 297-303.

[42] Lo, A.W. (2004). The adaptive markets hypothesis: Market efficiency from an evolutionary perspective. Journal of Portfolio Management, 30, 15-29.

[43] Lo, A.W., MacKinlay, A.C. (1988). Stock market prices do not follow random walk: Evidence from a simple specification test. The Review of Financial Studies, 1, 41-66.

[44] Lo, A.W., MacKinlay, A.C. (1990). When are contrarian profits due to stock market overreaction. The Review of Financial Studies, 3, 175-205.

[45] Lobato, I.N., Nankervis, J.C., Savin, N.E. (2001). Testing for autocorrelation using a modified Box-Pierce Q test. International Economic Review, 42, 187205.

[46] Mammen, E. (1993). Bootstrap and wild bootstrap for high dimensional linear models. The Annals of Statistics, 21, 255285.

[47] Marshall, B.R., Cahan, R.H., Cahan, J.M. (2008). Can commodity futures be profitably traded with quantitative market timing strategies? Journal of Banking and Finance, 32, 1810-1819.

[48] Morales, L., Andreosso-O'Callaghan, B. (2011). Comparative analysis on the effects of the Asian and global financial crises on precious metal markets. Research in International Business and Finance, 25, 203-227.

[49] Pukthuanthong, K., Roll, R. (2011). Gold and the dollar (and the euro, pound, and yen). Journal of Banking and Finance, 35, 2070-2083.

[50] Radetzki, M. (1989). Precious metals: The fundamental determinants of their price behaviour. Resources Policy, 15, 194-208.

[51] Riley, C. (2010). A new gold rush: Investing in Precious Metals, Journal of Investing, Summer, 95-100.

[52] Reboredo, J.C. (2013). Is gold a safe haven or a hedge for the US dollar? Implications for risk management. Journal of Banking and Finance, 37, 26652676.

[53] Roache, S.K., Rossi, M. (2010). The effects of economic news on commodity prices: Is gold just another commodity. The Quarterly Review of Economics and Finance, 50, 377-385. 
[54] Rockerbie, D.W. (1999). Gold prices and gold production: Evidence for South Africa. Resources Policy, 25, 69-76.

[55] Shafiee, S., Topal, E. (2010), An overview of global gold market and gold price forecasting. Resources Policy, 35, 178-189.

[56] Smith, G. (2002). Tests of the random walk hypothesis for London gold prices. Applied Economics Letters, 9, 671-674.

[57] Solt, M.E., Swanson, P.J. (1981). On the efficiency of the markets for gold and silver. Journal of Business, 54, 453-78.

[58] Tschoegl, A.E. (1980). Efficiency in the gold market. Journal of Banking and Finance, 4, 371-9.

[59] World Gold Council (2008). World Gold Council Publications Archive. www.gold.org.

[60] World Gold Council (2011). Gold: a commodity like no other. www.gold.org.

[61] World Gold Council (2013). Gold Demand Trends. www.gold.org. 